\title{
Recent trends in Air Transport Sustainability
}

\author{
Arturo Benito \\ Professor, Universidad Politécnica de Madrid, Spain \\ Gustavo Alonso \\ Professor, Universidad Politécnica de Madrid, Spain
}

\begin{abstract}
The target of this paper is to analyse the main elements of Air Transport sustainability, studying their evolution during the last years and establishing the future prevalent trends, which might be modified by the application of the adequate policies.

Air Transport sustainability is considered as integrated by five basic characteristics: physical accessibility, economic affordability, safety, security and environmental impact. Each one of them has its own influence on the development of this transportation mode and all of them are required in order to achieve a sustainable development.

After defining the structural elements of the five characteristics and the corresponding quantitative indicators, the paper studies the recent evolution of such indicators and extrapolates the most likely future trends, having taken into account the most relevant limitations presently existent or potentially appearing in the near future.

The most important policies being presently studied (future aircraft designs, infrastructure developments, potential safety and security new rules and tentative environmental action programs) are evaluated, considering the potential repercussions on sustainability progress. Some combinations of them are suggested as the most efficient alternatives for preserving the sustainable development of XXI century air transport.
\end{abstract}

\section{SUSTAINABILITY CONCEPT}

The concept of sustainability is relatively new. As a word, it does not appear, for instance, in the Oxford Dictionary, while in Webster's receives the definition of endurance of systems and processes. Oxford Dictionary does include the adjective sustainable, described as economic development that is conducted without depletion of natural resources, something very difficult to achieve. Other languages may or may not accept the word, but in those having captured it, that happens during the XXI Century. As a sample, Sostenibilidad appears for the first time in the Spanish Real Academia de la Lengua Española Dictionary in its $22^{\text {nd }}$ edition (2001).

A widely accepted definition of sustainability is contained in a 1987 report to the United Nations by the World Commission on Environment and Development, generally known as Brundtland Commission, from the name of its leader, a former Norwegian Prime Minister (BRUNDTLAND, 1987): 
"a development that meets the needs of the present without compromising the ability of future generations to meet their own needs"

The definition is straightforward and its meaning has been intuitively assumed by everybody. However, it hides a number of additional questions. How the needs of the present can be defined at worldwide level, considering the unbalanced situation of its different regions? Should only be counted the very basic needs, like food, lodging, health and education? And how to figure how are going to be the needs of future generations, in addition to the coverture of their basic survival requirements?

In spite of these uncertainties, the above definition was confirmed in 1992 by the first United Nations Conference on environment and development, held in Rio de Janeiro, and in the two subsequent Earth Summits in Johannesburg (2002) and Rio de Janeiro (2012)

\section{SUSTAINABLE TRANSPORT AND SUSTAINABLE AIR TRANSPORT}

The basic concept of Sustainable Transport merits some additional consideration. Transport, being a derived activity and not an end in itself, serves to a large number of primary activities (trade, business, culture, leisure, etc.), which must be sustainable in their own concept. Some of these activities are improved and/or grow, thanks to the value added by the involved transport, but others, like tourism, are very often directly created due to the existence of convenient transport services.

Those facts make advisable the movement from the classic sustainable transport development concept to the more advanced transport for a sustainable development, where the people needs, mentioned in the Brundtland definition are the centre of the problem. Notwithstanding this approach, mobility by itself, independently of the associated activity, has become a feature of modern societies and might be considered a people's right in many areas of the world (CRESSWELL, 2006).

In the present time, following this approach, the transport system must have the capacity to satisfy social needs of mobility and accessibility for people and goods, of trade, communication, social and cultural relationship, without limiting other essential values in the human, social and ecological fields. And all those achievements must not compromise the ability of future generations to reach them as well (MOOTIEN, 2012).

According to the Maastricht Treaty (EU, 1992), which has a substantial part addressing sustainability, the European Union would be using a number of policy instruments to foster its development: 
- General economic incentives (market based measures like ecological taxes or fiscal incentives)

- Specific incentives per transport mode or effect (penalising or not certain environmental impacts)

- Specific regulations per transport mode or effect (limiting the magnitude of some effects or controlling pricing)

- Complementary transport coordination policies (looking for the optimum modal transport combination)

Those instruments will take into account all the transportation services economic effects, and classify them in the traditional four groups: direct, indirect, induced and dependent, without leaving aside the social impacts and the environmental footprint. The policies and actions must follow the general guidelines of the United Nations Economic and Social Council (ECOSOC) and its regional body United Nations Economic Commission for Europe (UNECE), who works for the application of sustainable development policies, including common regulations adapted to the international transport needs.

The five action areas defined by this organism (UNECE, 2011) in order to evaluate the economic, social and environmental effects of transport and therefore its contribution to a sustainable development are:

- Physical accessibility. Physical barriers to the transport mode use, as distance to the transport terminals or physical capability of the users.

- Economic accessibility. Price barriers for the different population income layers.

- Safety. Statistical possibility of suffering an accident when making use of the transport vehicle or facilities.

- $\quad$ Security. Statistical possibility of suffering a menace, attack or robbery.

- Environment. Local and global environmental impacts.

Within the aviation sector, the main stakeholders (airlines, airports, air navigation service providers, and aircraft, engine and system manufacturers) signed in March 2012 the document Towards sustainable aviation (ATAG, 2012) explaining their targets in this field and the areas in which Government participation is needed to reach the expected results. Among those areas it were mentioned the coordination of international academic and industrial research investments, the improvement of infrastructure, both Air Traffic Control and airport capacity, a framework of uniform worldwide environmental regulations under the International Civil Aviation Organisation (ICAO) leadership and a general agreement to reduce international civil aviation emissions, with a clear quantitative target. A particular mention asked for a balanced approach to the different transportation means by the Administrations. 


\section{THE AIR TRANSPORT SECTOR DIMENSION}

With 2015 figures, the air transport sector includes about 26,500 commercial aircraft in service, operating 36.4 million flights in 3,800 airports, controlled by 180 air navigation organisations. Over 1,570 airlines moved about 3,500 million passengers and, counting together passengers, cargo and mail, achieved a transportation volume of 750,000 million Revenue ton-kilometre (RTK). Total world airline revenue was over 710,000 million US dollars (USD).

In terms of socioeconomic impact, 58 million jobs are depending of activities related to air transport, with an economic volume of 2.5 trillion USD in the world GDP. The highest expense for airlines was the fuel, having paid more than 180 billion USD for 245 million of kerosene $\mathrm{kg}$ corresponding to $774 \mathrm{CO}_{2}$ million ton emissions.

The existing predictions are practically unanimous about a future continuous growth, higher than the word GDP increase, with consensus yearly rates in the order of $4.5-5.0 \%$ in terms of passenger kilometre (RPK) and $3.5-4.0 \%$ in ton kilometre, adding the volume of transported freight. Figure 1 (AIRBUS, 2015) shows the historical RPK trend and the future projections.

It is interesting to observe that the important turbulences of the September 11, 2001 terrorist attacks and the 2008-2010 financial crisis do not substantially modify the long term growth trend.

This and other forecast are assuming an unconstrained scenario, where the air transport services supply follows the demand evolution with the present level of technical and regulatory constraints. The introduction of new and/or additional restricting conditions would change the long term results.

Most of the analysis on air transport contribution to sustainable development has been made from a qualitative point of view, considering that the quantitative aspects were included in the sustainability evaluation of the activities supported by air transport. Some exceptions (JANIC, 2007) are of partial nature or apply to specific markets (RYLEY et al., 2013), looking at the present situation at the moment of publishing the paper, leaving a wide field for further studies on future scenarios projections. The European Union has recently made some efforts to systematize the analysis, but always within its geographical limits (EU, 2013), offering results not applicable to the whole world. 


\section{TRAFFICWILL DOUBLEIN THE NEXT 15 YEARS}

Sources: ICAO, Albus GMF 2015

RPK - Plevenue Passenger Kllometer

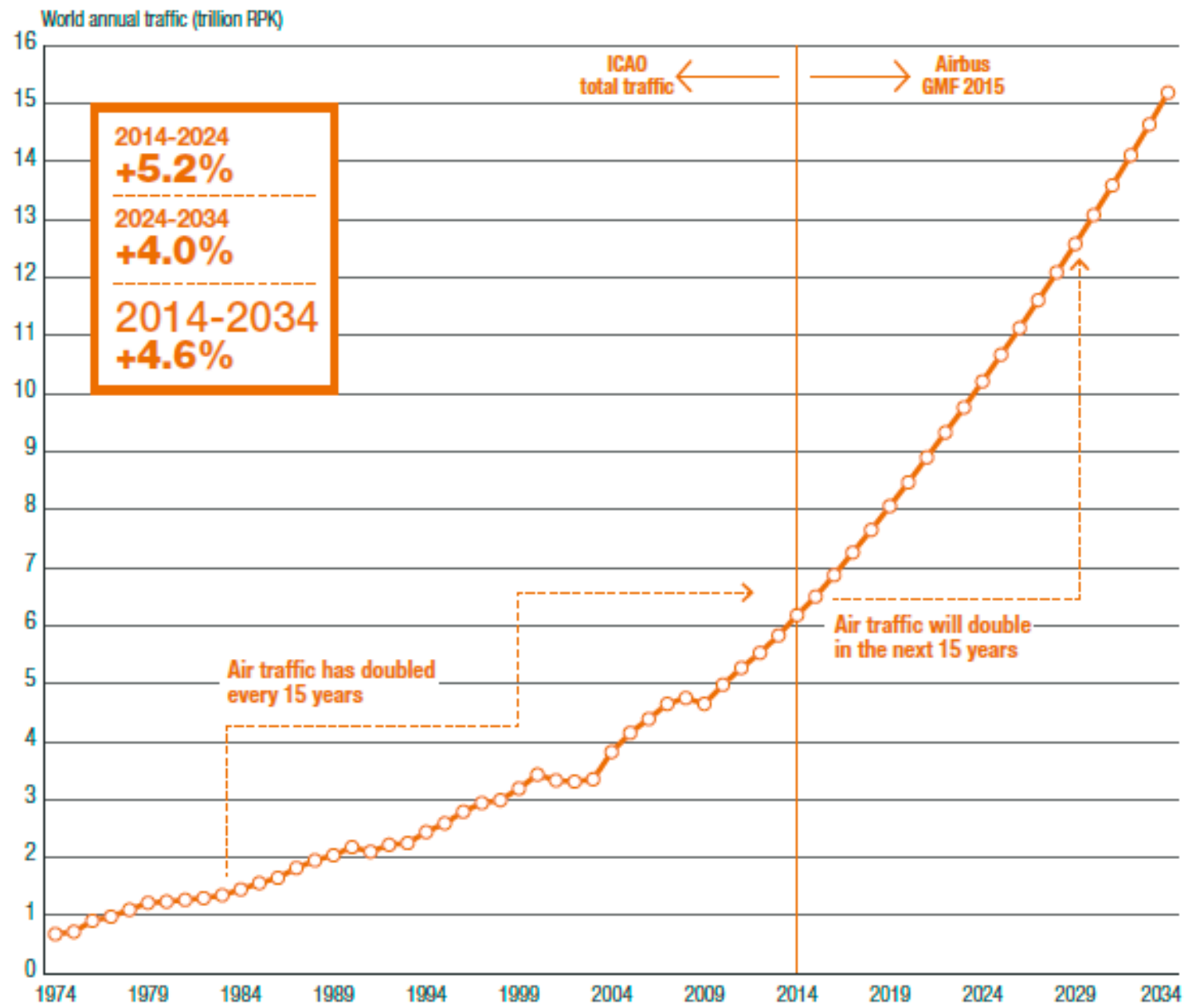

Figure 1 - Historical and forecast traffic growth

\section{Accessibility}

As an essential factor for a great number of activities, Air Transport needs to be accessible to a majority of the population in order to be considered sustainable. This feature has three different elements: how easy is reaching the air transport terminals, how accessible is the air transport system for reduced mobility people and how affordable is the trip for average personal economies.

\subsection{Reaching air terminals}

There are roughly 3,800 commercial airports in the world, an average of more than one per 2 million Earth inhabitants. The spatial distribution of those airports is following the population density and the economic development of the different regions with unequal 
planning system, generally adapted to the geographical features of each territory.

As an example of integrating accessibility program, the European Union (EU, 2011) has among its goals that $90 \%$ of travellers within Europe will be able to complete their journey, door-to-door, within four hours. This includes passengers and freight being able to transfer seamlessly between transport modes to reach the final destination smoothly, predictably and on-time.

Obviously this target is not feasible for the Air Transport in isolation. It requires a high degree of coordination and compatibility between Air transport and the Surface transport industry, and a lot of innovation and emerging technology for intelligent mobility.

As airports are zones where aviation environmental impacts are more acute, some of these effects, like noise, may be a limiting factor for their development. An active policy of reducing airport noise and carbon footprints by introducing clean energy generators, promoting collective transport access and a noise efficient land use planning, is an essential requisite for avoiding obstacles in the infrastructure build up.

\subsection{Reduced mobility people}

The measures for making reduced mobility people able to access Air Transport cover three different areas. On one side, airports have to be designed for accepting people moving in wheelchairs or other helping devices, considering mobility needs but also the security inspections. As a second step, the aircraft should provide enough flexibility to accommodate these persons in both passenger seats and other cabin facilities like toilets. The typical narrow space of small aircraft makes difficult to have dedicated facilities and regional aviation suffers a chronical deficiency in this aspect.

The third and more difficult point is to implement the tools required for disabled people emergency evacuation. At this moment this aspect is solved by the requisite of an accompanying person and a limitation of the number of disabled people to be accommodated in any particular flight.

\subsection{Air Transport affordability}

Air Transport started its life as an expensive mode of transport only affordable by wealthy people. As aircraft technology was developing, travel cost was reduced, a factor helped by Airlines adopting more efficient company structures and increasing levels of competition as flying commercial regulations were being liberalised. This process is still running and may take some years to be spread along the world up to the same extent of today's North America and Europe, but its effects are being noticed in a large part of Middle East, Asia Pacific and Latin America. 
A combined effect of the increase in number of routes and the reduction of travel price can be seen in Figure 2 covering the 1994-2014 period. The increasing trends in number of city pairs served by air transport practically doubled while the cost of travel was halved. It is worthwhile to notice that the number of city pairs refers to single flight connections and does not take into account trips with an intermediate stop as large carriers use to promote through their hub and spoke airport systems.

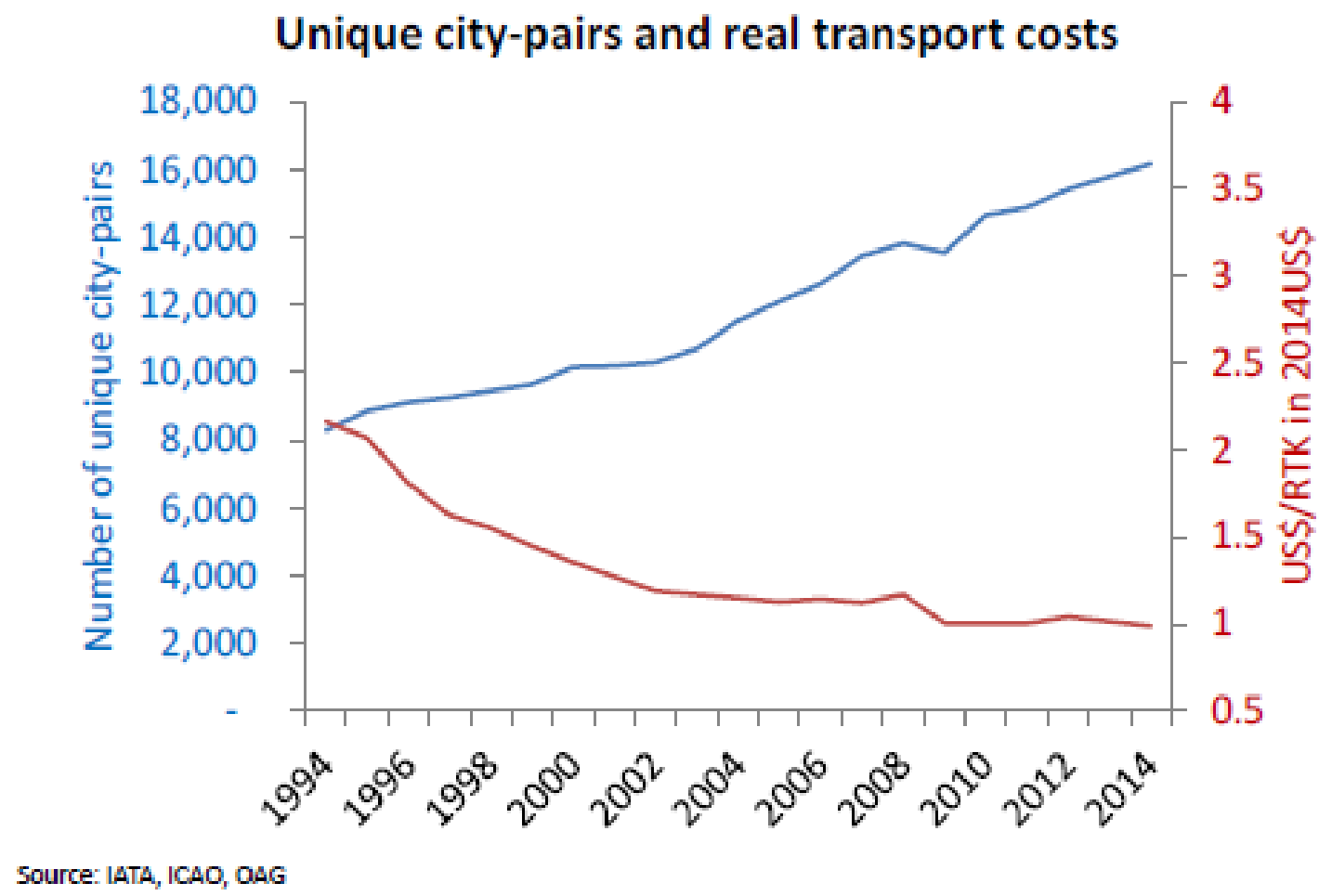

Figure 2 - Direct route number and average ticket price in the 1994-2014 period

The total number of air trips depends on the purchase capacity of the population and the geographic conditions of the region that is influential for the modal competition as well. Figure 3 gives an idea of the relationship between GDP per capita and the number of air trips per inhabitant. As the logarithmic curve has a high slope at low GDP values, relatively small increases in economic conditions produce great growth of trip numbers, a condition that includes a number of highly populated countries like China, India, Brazil, Indonesia or Russia, with emerging economies showing a large growth potential.

An important factor for the accessibility problem is the liberalisation of the international traffic rights. The Chicago Convention, legal milestone of the international civil aviation system, grants Member States the right of decide who may operate in their air space. Domestic flights are below the authority of national authorities and international flights with no commercial purposes need no special permission, but pure commercial flights between two States need approval of both countries through a bilateral international agreement. Thousands of those agreements around the world determine the permissible amount of offer 
and competition level in international aviation market.

After United States liberalised its aviation market in 1983 and the European Union made the same ten years later, the trend of eliminate bilateral agreements and allow open competition has been gaining ground. Some Middle East, Asian and Latin American countries are created liberalised traffic right zones and, with increased competition, fares go down and air travel affordability increases.

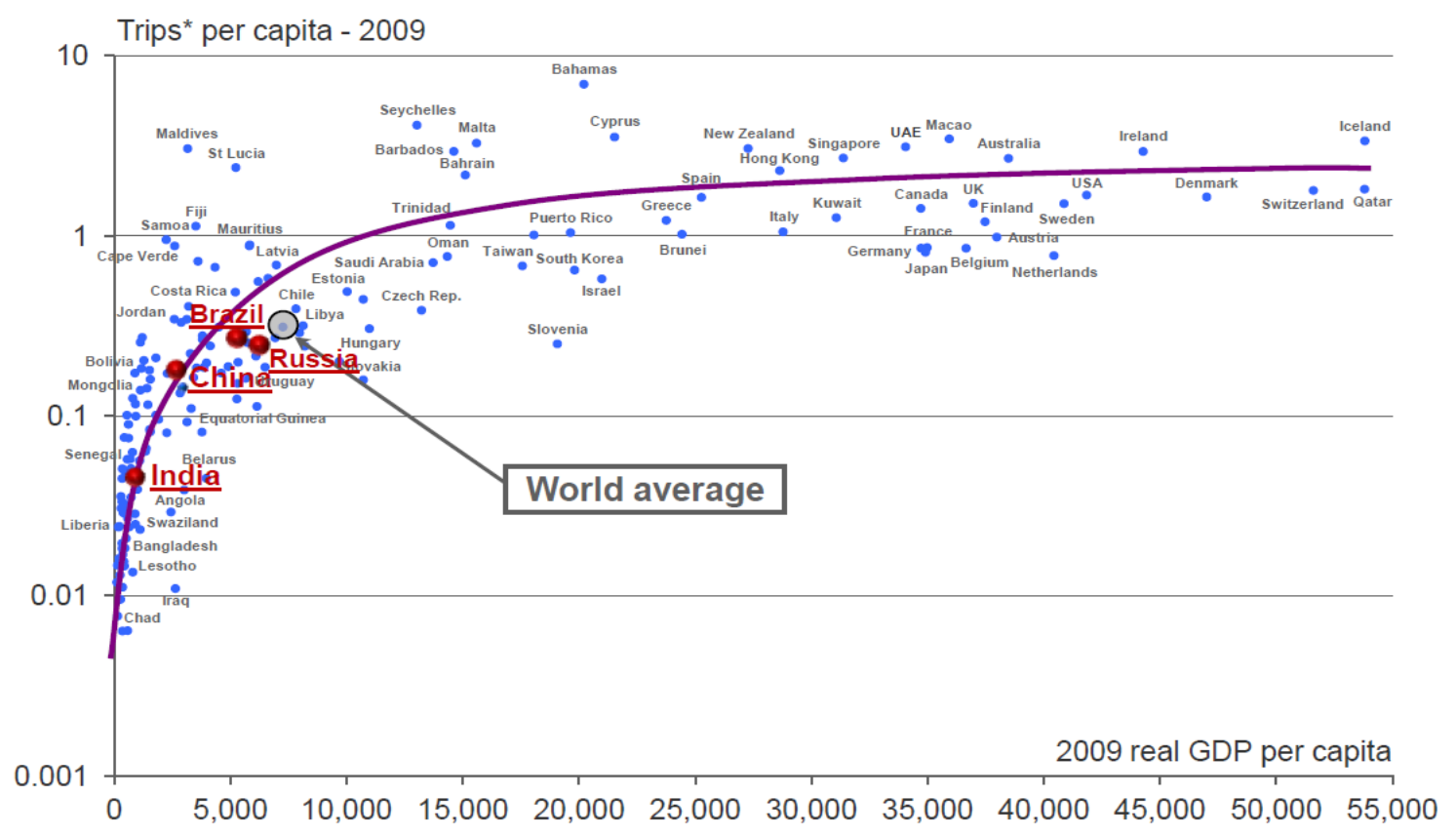

Figure 3 - Relationship between national GDP and number of air trips per capita

\section{Safety \& Security}

As any other transportation mode, Air Transport devotes great efforts to minimize the possibilities of an accident during the user travel. These rare occurrences generate a lot of coverage by world media and negative image for airlines. As the same time, the high visibility of the air mode to the public communication systems provides an incentive to violent groups and organizations for committing attacks looking for the immediate repercussions in the media.

\subsection{Safety}

Air Transport safety system is based in a worldwide technical standards base, subject to a continuous and transparent control, structured in seven consecutive elements:

- Design: the design of the commercial aircraft has to follow international regulations and is supervised by the competent authorities who have to approved the project, the methodology and the calculations 
- Manufacturing: the materials and the processes need to be certified as well. The civil aviation authorities undertake inspections during the construction and the assembly of the aircraft

- Certification: All the elements of the mode, vehicle and infrastructure, have to undergo a strict certification process before entering into service. In the case of the aircraft and the air navigation services, this has been made since the very beginning of the modern commercial aviation. Airport certification is relatively new and is being applied in somewhat different ways around the world, but is in its way to be made more homogeneous under the ICAO umbrella

- Maintenance: Both organisations doing maintenance and the used facilities need to be certified under the rules of the State where the aircraft is registered. Maintenance work is performed following approved Manuals and the operative maintenance status is periodically inspected by civil aviation authorities

- Operation: ICAO establishes worldwide operational procedures and the rules to issue the perceptive licenses, with periodic renewals, to the operating personnel (pilots, controllers, maintenance technicians and dispatchers)

- Exploitation: Commercial operators are required to obtain an AOC (Air Operator's Certificate) as a guarantee that the airline is fitted for its declared mission

- Accident investigation: Common procedures for investigation of accidents and incidents, according to Annex 13 to Chicago Convention, with full dissemination of conclusions and recommendations

There is not widely accepted single metric to measure the global safety improvement pace. The database may include all commercial flights, only jets or just Western built jets, excluding those manufactured in Eastern countries during the Cold War period. Metric may account for number of people dead or injured per flight, flight hour or passenger-kilometre. Number of hull losses is other commonly used metric, but whatever the selected unit, the time evolution shows a decreasing trend.

Figure 4 (Boeing, 2015) gives a long period accounting of some of these metrics. The dimension of annual number of dead passenger per year is less than 1,000 , about 0.3 per million of trips. In 2015, the only two jet accidents with fatalities were results of a bomb explosion and a suicide pilot.

Although commercial airlines regulations have always compelled to have a continuous improvement safety program in each company, the approval of the new Annex 19 to Chicago Convention in 2013 stretched that mandate to the airports and air navigation organizations, including a certification and monitoring program, with the purpose of placing all the elements of the air transport system under the same safety conditions. 


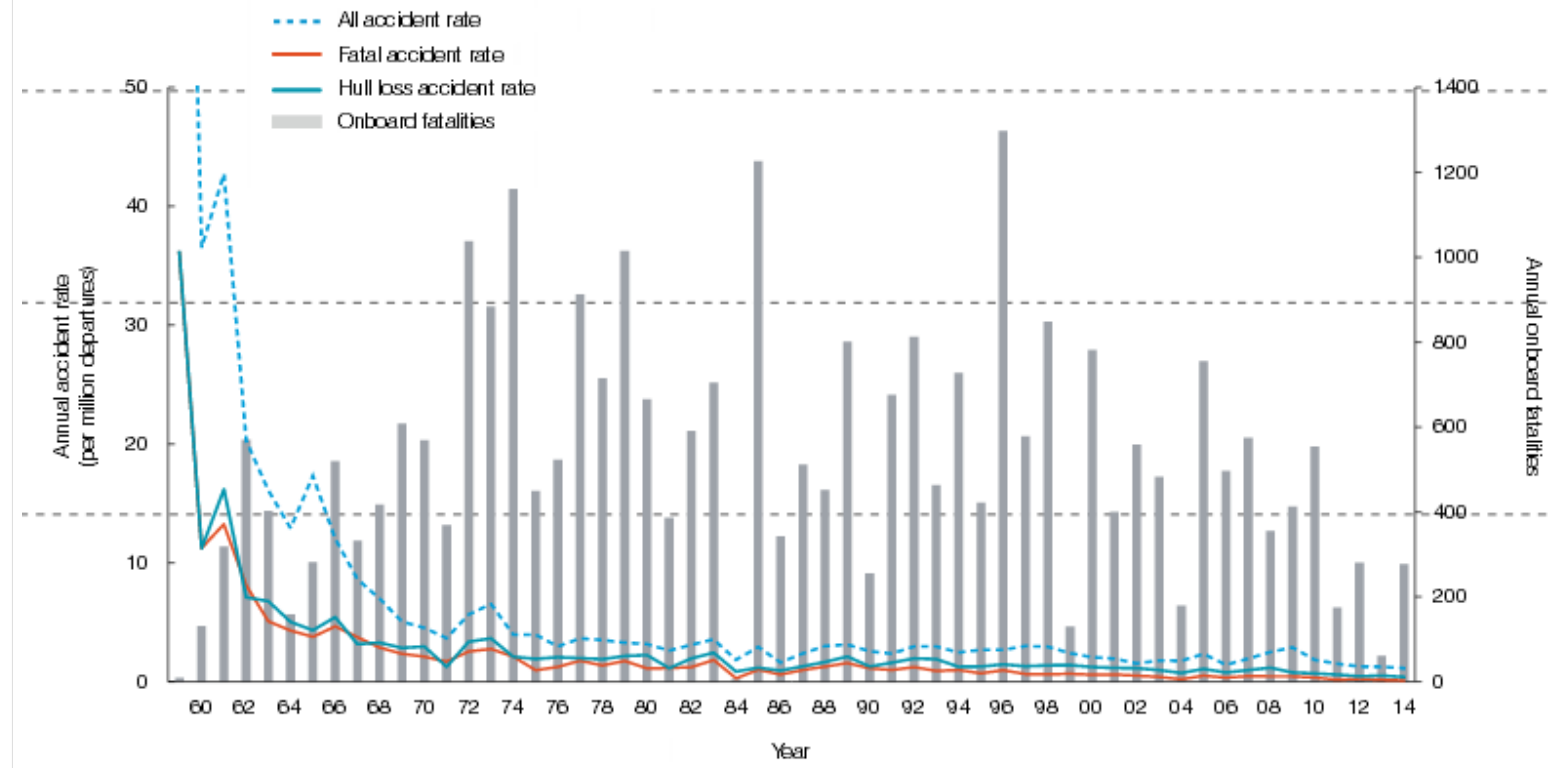

Figure 4 - Accident rates for commercial jet aircraft

\subsection{Security}

As in the case of safety, Air Transport security system depends on widely accepted security standards, coordinated by ICAO and implemented by each one of its Member States. Conceptually safety is ensured by intensive control of the access to a security perimeter built around the airport area, where only accepted vehicles and personnel are allowed to penetrate.

The system has two levels of defence: a first one marked by the security forces restricting the access of anybody not related with the airport and airline operation. Accepted personnel is divided in passengers passing through the security control with a valid travel title and airport workers having a private authorisation to move inside this perimeter, including airport operator workforce, civil aviation authority clerks and commercial facilities and airline employees.

The second level is the access to the ramp (the airside of the airport), reserved for crews and handling personnel, and to the interior of the aircraft, limited to passengers and crews. After the terrorist attacks of September 11,2001, commercial airliners have shielded cockpit doors to avoid possible intrusion of passengers during the flight.

According to official statistics (ICAO, 2014) the number of illicit acts against civil aviation during the last 20 years shows a diminishing trend, deeper if the used parameter is the 
number of persons dead as a consequence of them (see Figure 5)

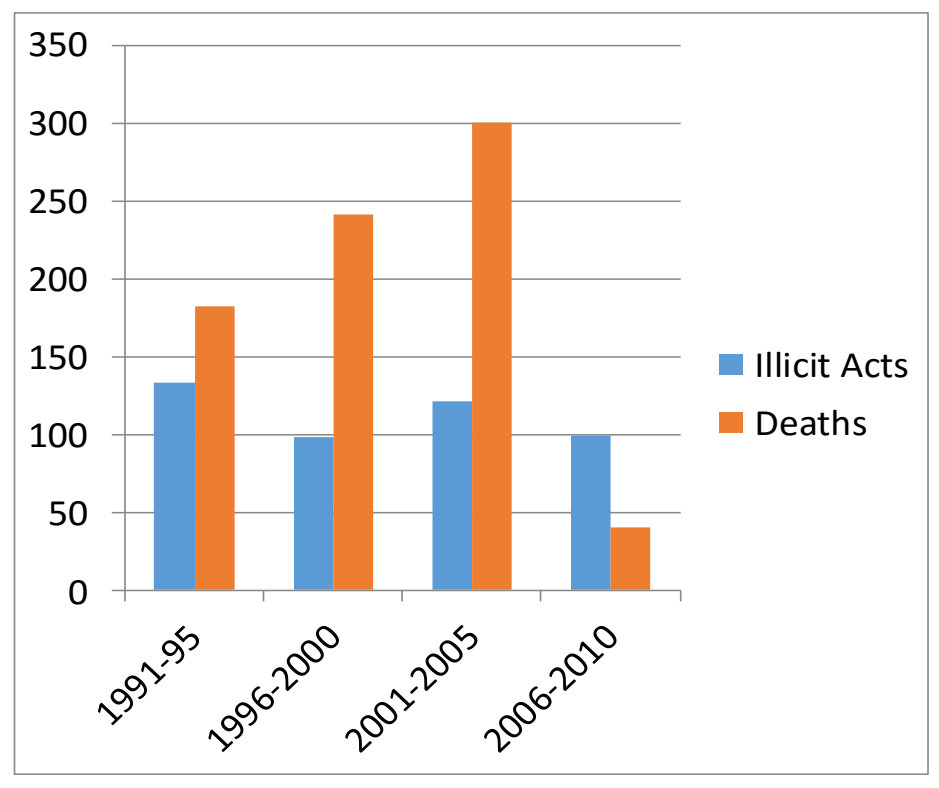

\section{Figure 5 - Evolution of world aviation security (11-S figures not included)}

However the classification of these illicit acts is not homogeneous because some of then has happened outside the controlled access perimeter, like the recent Brussels airport attack. A majority of them are menaces with more or less fundament, but an increasing level of security measures on anything related to air transport is vey likely to be implemented in the near future.

\section{Environment}

The environmental impact of Air Transport uses to be divided in two main categories:

- Local impacts when the effects of which are only perceived in the area close to the airports, including noise, emissions affecting air quality and airport natural habitat deterioration.

- Global impacts having a worldwide repercussions like emissions affecting climate change, non-renewable materials consumption and use of the radio-electric spectrum.

\subsection{Local effects}

The most important local environmental effect of Air Transport is no doubt the noise around the airports. The modern concept of large airport is not anymore a pure transport terminal or a modal interchange facility, but a real conglomerate of transport, commercial and urban complex highly populated. During the last three decade, the advances of acoustic technology have more than compensate the flight number increase and the number of people subject to 
a substantial noise annoyance has been continuously reduced, but the latest ICAO calculations show a different scenario for the next decades with small increases in the ground surface affected by aircraft noise.

ICAO regulations ask for acoustic certification of all the new civil aircraft types and set up stringency levels representing the best existing technologies at the time of the regulation approval. The maximum permissible levels are known by their corresponding Annex 16 chapter and its evolution is represented in the Figure 6. Chapter 2 entered into force in 1972, Chapter 3 in 1977, Chapter 4 in 2006 and Chapter 14 will be applicable in 2018. It is clear that the marginal noise reductions are being smaller each time, because the present aircraft geometry gives little margin to more improvements.

\section{ICAO Noise Certification Standards}

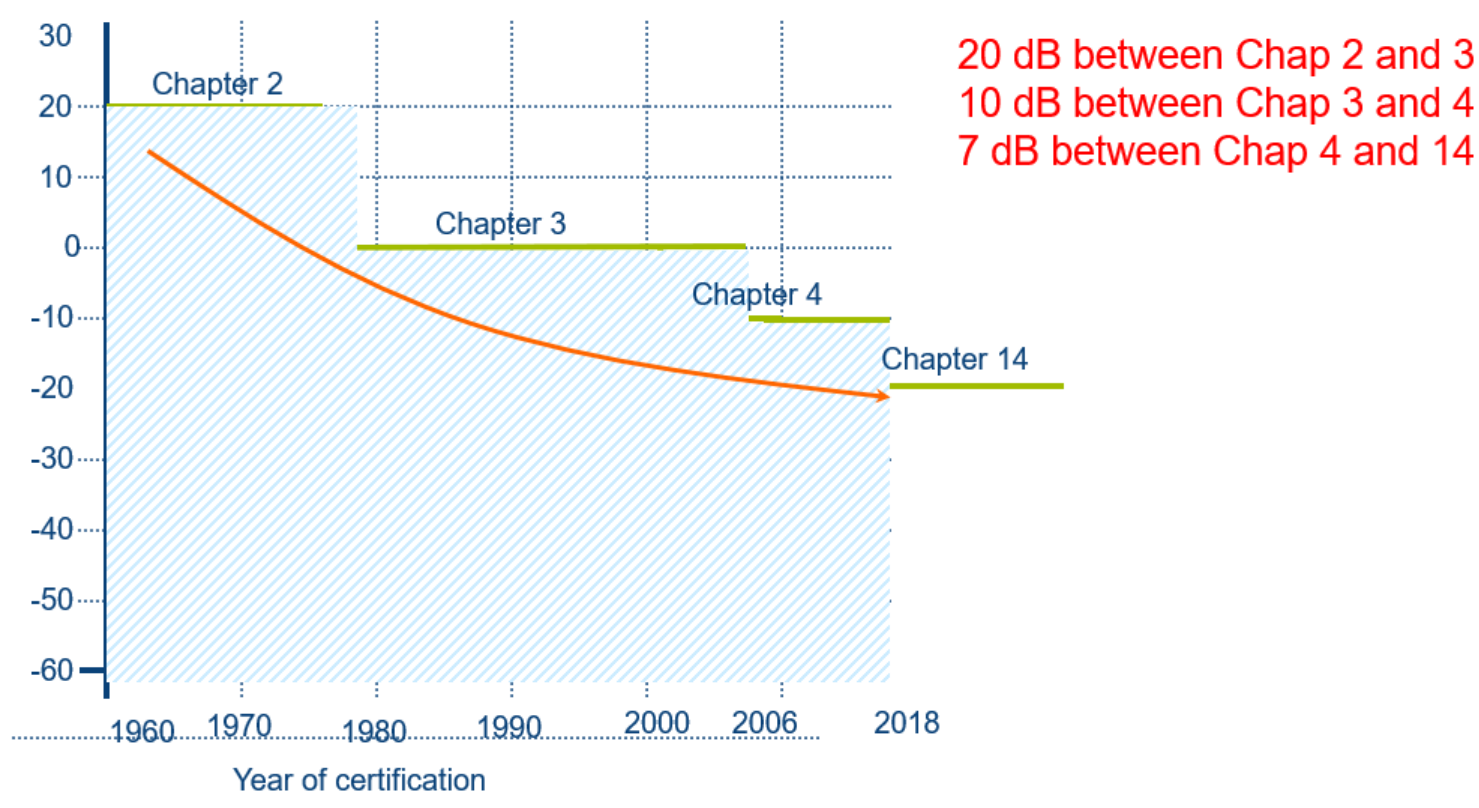

\section{Figure 6 Evolution of the aircraft acoustic certification levels}

The key factor that makes this trend dangerous is the failure to implement land use planning programs avoiding encroachment (houses being built closer to he airports, within the noise footprint to be avoided). A second factor to be taken into consideration in developed countries is the reducing tolerance to noise environment, making annoying some noise levels that have been tolerated years ago.

As land use competence around airports uses to be on hands of local authorities, no wide coverage regulations are in force. The EU initiative to ask for mandatory noise footprints analysis around big cities, industrial areas and large transportation infrastructures may provide an initial step towards the creation of some world standards in this area. 


\subsection{Global effects}

With the present economic conditions and the existing forecasts, the prime element of concern is the air transport contribution to climate change. The most authoritative sources (IPCC, 1999) and further reviews offers a figure of 3.5-4.0\% of all anthropogenic impacts on atmospheric warming, but only about $60 \%$ of those (basically $\mathrm{CO}_{2}$ emissions) have been assessed without any doubt while the rest (effect of nitrogen oxides emissions, condensation trails, water vapour) are still being studies in order to obtain a precise quantitative evaluation. During the last 15 years, most of the mitigation measures have been targeted on $\mathrm{CO}_{2}$ reduction.

The overwhelming majority of commercial aircraft burns kerosene mostly obtained by distillation of fossil oil, although some small amounts are made out of carbon powder by the Fischer-Tropsch chemical process. Every kilogram of burned kerosene produces $3.16 \mathrm{~kg}$ of $\mathrm{CO}_{2}$ and, although commercial aviation sector has been able to improve fuel efficiency, in terms of fuel $\mathrm{kg}$ per RTK, at a $1.5 \%$ yearly rate in the best case, this figure is unable to compensate the air transport annual growth, in the order of 3.5-4.0\%. Recent analysis of some developed markets (AMIZADEH et al. 2016) show lower figures. As a consequence, aviation $\mathrm{CO}_{2}$ emissions were over 750 million ton in 2015 and are expected to grow $2.0-$ $2.5 \%$ per year in the near future.

Mitigation measures have been studied, focusing in four different elements: technological improvements in aircraft, engines and systems, optimisation of operating procedures, development of aviation infrastructure and, last but not least, market based measures, including taxes, charges, voluntary agreements and emissions trading, within the framework approved for other activities by the United Nations Framework Convention on Climate Change.

Air transport is in a curious regulatory situation because domestic flights greenhouse gas emissions like $\mathrm{CO}_{2}$ are included in national inventories and subject to national mitigation policies, but international flights are subject to the ICAO authority. After a very long and hectic negotiation process, the 38 ICAO Assembly (ICAO, 2013) established a target of achieving Carbon Neutral Growth after the year 2020 and reducing $\mathrm{CO}_{2}$ emissions by 50\% in the year 2050 (Figure 7). 


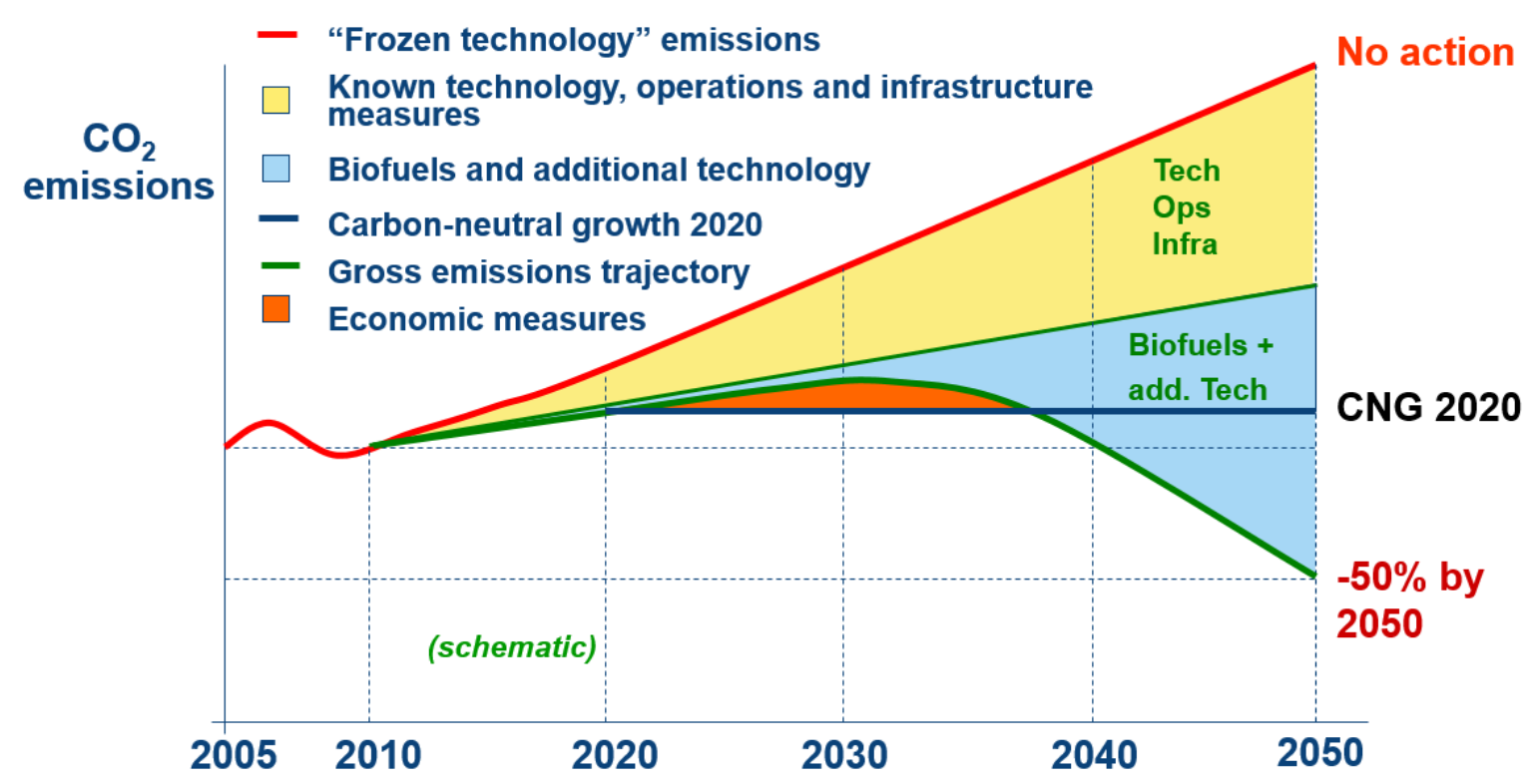

\section{Figure 7 - Schematic description of ICAO plan to mitigate aviation climate change contribution}

As it can be seen in the schematic figure, the key element of this plan is the availability of biokerosene at large scale, starting in the next decade. In spite of intensive research in liquid hydrogen, fuel cells or electric power, the use of a different energy source for commercial flying seems unlikely at least during the next decades and practical applications are now centred in drop-in fuels (with similar properties than fossil kerosene) obtained from vegetable raw materials non competing with food supply, like camelina, jathrofa or algae. The $\mathrm{CO}_{2}$ absorbed by the plants during their growth phase may compensate in a life-cycle basis up to $80 \%$ of their combustion $\mathrm{CO}_{2}$ emissions.

In the present market conditions, the production of biokerosene at a price competitive with the kerosene from fossil fuel distillation seems almost impossible and some market based measures are needed, at least during some years to overcome this problem. It is assumed that in a period of 20 years, the use of market instruments will not be necessary and biokerosene production will be progressively replacing its fossil counterpart.

\section{Conclusions}

Future air transport evolution in the framework of a sustainable development has to be considered taking into consideration all the three economic, social and environmental elements in the five action areas of physical and economic accessibility, safety, security and environmental impact. Measures trying to improve the situation of a single element or one isolated action area risk to modify more than mitigate the problem. 
Infrastructure development and modal coordination are key factors for both physical and economic accessibility. The experience of the last three decades show that commercial conditions liberalisation, allowing easier market access, improve enormously the economic affordability of air transport, independently of the world region and the prevalent economic regime. A likely scenario is duplicate the number of air trips in the course of the next 20 years.

Existing safety system has proved to be very efficient in reducing accident rates in a continuous way. The introduction of advanced satellite-based navigation systems and more redundant man-machine interface should move the fatal accident rates to the 1 every 20 million flights in the above mentioned period.

Security remains more difficult to face due to the instability of the political situation and the visibility of air transport for the media. New trends are based on keeping and improving the existing access control system and, at the same time, introducing personal profiles at large scale as a complementary measure.

Finally, the environmental sustainability needs to be reached through the implementation of the Carbon Neutral growth plan that will be inserted in the panel of actions to be developed after the ratification of April 22, 2016 New York agreement to keep atmospheric warming below 2 centigrade in this century.

\section{REFERENCES}

AIR TRANSPORT ACTION GROUP (2012). Towards sustainable aviation. Geneva.

AIRBUS (2015). Global Market Forecast. Toulouse.

AMIZADEH, F., ALONSO, G., BENITO, A., MORALES-ALONSO, G. (2016). Analysis of the evolution of comercial air traffic $\mathrm{CO}_{2}$ emissions and fleet utilization in the six largest national markets of the EU. Journal of Air Transport Management, Vol 55, pp. 9-19.

BOEING (2015). Boeing Safety Report. Seattle.

BRUNDTLAND, G. (1987). Our common future. United Nations, New York.

.CRESSWELL, T. (2006). The right of Mobility. The production of Mobility in the Courtroom. Antipode, Vol 38, Issue 4, pp. 735-754.

EUROPEAN UNION (1992). Maastricht Treaty. Brussels. 
EUROPEAN UNION (2011). Flightpath 2050 Report - European vision for aviation. Brussels.

EUROPEAN UNION (2013). Increasing the sustainability of Air transport, Communicating transport research and innovation. Brussels.

FORSYTH, P. (2011). Environmental and financial sustainability of air transport. Are they incompatible? Journal of Air Transport Management, Vol. 17, Issue 1, pp. 27-32.

INTERGOVERNMENTAL PANEL ON CLIMATE CHANGE (1999) Aviation and the global atmosphere. Cambridge University Press.

INTERNATIONAL CIVIL AVIATION ORGANISATION (2013). Assembly Resolution A38-18. Montreal.

INTERNATIONAL CIVIL AVIATION ORGANISATION (2014). Annual Report. Montreal.

JANIC, M. (2007). The sustainability of Air Transportation. A quantitative analysis and assessment. Ashgate, Farnham (UK).

MOOTIEN, N. P. (2012). Air Transport and sustainable development; what complementarities and compatibility for the future? Global Journal of Human Social Science, Vol. 12, Issue 4. Pp. 25-32.

RILEY, T., BURCHELL, J. and DAVISON, L. (2013) Valuing air transportation and sustainability from a public perspective: Evidence from the United Kingdom and the United States. Research in Transportation Business and Management, Issue 7, pp. 114-119.

UNITED NATIONS ECONOMIC COMMISSION FOR EUROPE (2011). Transport for sustainable development in the ECE region. Paris. 